\title{
Developing a Model for the Evaluation of Iranian EFL Teachers' Awareness of the Code of Ethics in Research
}

\author{
Farideh Samadi ${ }^{1}$, Khalil Motallebzadeh ${ }^{1,2}$, Hamid Ashraf ${ }^{1}$, \\ Gholam Hassan Khajavy ${ }^{3}$ \\ ${ }^{1}$ Islamic Azad University \\ ${ }^{2}$ Tabaran Institute of Higher Education \\ ${ }^{3}$ University of Bojnord
}

\begin{abstract}
Correspondence concerning this article should be addressed to Khalil Motallebzadeh, Department of English, Torbat-e Heydarieh Branch, Islamic Azad University, Torbat-e Heydarieh, Razavi Khorasan Province, Iran. E-mail: k.motalleb@iautorbat.ac.ir
\end{abstract}

\begin{abstract}
Conducting educational research is not an arbitrary practice. When implementing educational research, teachers, as researchers, need to adhere to ethical rules and norms. Thus, developing an instrument for evaluating English as foreign language (EFL) teachers' awareness of the code of ethics in research can guide Iranian ELT professionals to work towards setting standards in the assessment of Iranian EFL teachers' professional development and may assure consistency in EFL teachers' quality assurance. The principal determination of the present study was to develop a scale to evaluate EFL teachers' awareness of the code of ethics for conducting research in Iran. This work's theoretical framework is based on the most influential ethical issues and elements in research in Samadi, Motallebzadeh, Ashraf, and Khajavy's (2020) study. To this end, 272 Iranian EFL teachers (chosen using convenience sampling) participated in the analysis to fill out the scale in the piloting stage. The scale consisted of five main categories: (F1) Before the beginning of the research, (F2) the Beginning of the research, (F3) Gathering the data, (F4), Analyzing the data, and (F5) Writing, reporting, sharing, and storing the data. The first draft of the scale consisted of 60 items. As part of the validation procedure, the reliability of this scale was determined through Cronbach's alpha, and its validity was measured by running a confirmatory factor analysis (CFA) through a structural equation modeling approach. After performing the CFA, it was found that the questionnaire had high construct validity. Finally, the statistical findings were presented, and the implications of the ELT domain were given. The findings provide empirical evidence that provides a framework for assessing and evaluating EFL teachers' awareness of the code of ethics in research
\end{abstract}

Keywords: Code of ethics, EFL, Research, Teachers' awareness, Iranian

\section{Introduction}

Inquiries into English as a foreign language (EFL) acquisition or education has extended positively during recent years. Research plays a crucial part in education. Research attempts to uncover new knowledge through critical and systematic investigations and peer review. It also "aims to generate (new) information, knowledge, understanding, or some other relevant cognitive good, and does so by utilizing a systematic investigation" (Baer, 2010, p. 14).

Teachers are expected to keep abreast of the changes and improvements in their field. As such, they need "to be knowledgeable consumers of educational research" (Best \& Cahn, 2006, pp. 107-119).

Furthermore, teachers' performances in their classrooms require constant examination. To do this, they need to compare their practices with different methods applied in similar circumstances by other teachers. They may carry out action research to find out if a procedure works for them or if they need to try something else with a specific pupil or classroom. 
Conducting educational research is not an arbitrary practice. When implementing educational investigations, teachers, as researchers, need to adhere to ethical rules and norms. In addition, an essential aspect of research is unpredictability in terms of the results of research, its potential benefits, and the risks involved (Baer, 2010). Ethics, in addition to culture, customs, habits, regulations, and even traditions, is an important issue that builds a society. The term 'ethic' has various meanings based on the context. "Sometimes, ethics means moral values; other times, it means legal limitations on behavior and understood community standards (Özturk, 2010, p. 394). Ethics are standards of right and wrong that specify what people ought to do or ought not to do in social situations. It is a set of social practices (Davies, 2004). Ethics refers to standards for defining levels of goodness or interest. Ethics is commonly loaded with affective judgments about ideas, matters, actions, etc.

Ethical issues in research are vital. They help researchers avoid the production of false information. They promote the search for perception and precision as the basic aim of any study. Furthermore, honesty, openness, systematisms, and records are essential requirements for conducting research. In addition, investigators have a duty to "preserve the lifespan, healthiness, self-esteem, trustworthiness, independence, and intimacy of private data of research participants" (World Medical Association, 2013, pp. 2191-2194). Ethical conduct is similarly crucial for cooperative tasks since it urges an atmosphere of trustworthiness, responsibility, and interactive honor with investigators. This is particularly critical regarding "data sharing, co-authorship, copyright guidelines, confidentiality," and other factors. Furthermore, researchers should comply with ethical norms in order for the community to support and trust their research. The people of the community need to be assured that investigators are following suitable ground rules regarding matters like people's benefits, informed consent, and conformity to the rules, accountability, security, and confidentiality. Whether these ethical issues are considered influences the integrity of the research project significantly (Mazur, 2007).

Ethical issues are essential in research, as well as in any other educational activity, and researchers should adhere to these ethical issues in every step of their research. Ethical education is vital at every point of our lifespans. Nevertheless, it is very difficult to functionalize how to define and show the levels and restrictions of ethics (Farhady, 1999).

Regarding the importance of ethical issues in research, many academic institutions and departments have developed codes that define ethical behavior to guide researchers with regard to the relevance of ethical issues. Such codes and standards include notions like informed consent, confidentiality, fairness, accountability, confidentiality, and objectivity. Such codes and standards also provide primary guidelines. However, investigators still face specific concerns that are not clearly discussed in these codes, and this allows researchers to make decisions to prevent misconduct (Mazur, 2007). Furthermore, as professionals, teachers as researchers are required to follow a set of rules for ethical conduct in research. In addition, a validating tool for assessing ethical conduct is needed.

A significant amount of research in past decades has been conducted and has added to our knowledge about teaching, testing, and assessing (Malta, 2012, Sterling \& Gass, 2017; Thrasher, 2011). However, ethics has not been treated as a significant and critical topic in English language teaching (ELT) research. For instance, Thrasher (2011) investigated a code of ethics in language testing. Malta (2012) developed a code of ethics and practice for teachers. As there is not any questionnaire about teachers' awareness of the code of ethics in research found in the literature in the field of language teaching, a gap (lack of a model for ethical codes in research for Iranian EFL teachers) is present.

In order to fill this gap, a scale reflecting the code of ethics in research was designed and validated in this study. The present study also proposes a new code of ethics model to be used by Iranian EFL teachers who carry out ELT research.

\section{Literature Review}

\section{Theoretical Framework}

The theoretical foundation of the current research is founded on ethical principles suggested by the claims of Samadi, Motallebzadeh, Ashraf, and Khajavy (2020). Our study was the first published with the same aim as the 
current study. The researchers' intention was to develop an inventory for the Iranian EFL teachers' awareness of the code of ethics for research contextualized for Iran. As teachers' awareness of the code of ethics is not found in any questionnaires in the literature, we cannot compare the results. Thus, this study has its own novelty in this way. The study revealed that EFL teachers' awareness of the code of ethics in research is synergistically influenced by a range of factors: (a) Before the beginning of the research, (b) the Beginning of the research, (c) Gathering the data (d) Analyzing the data, and (e) Writing, reporting, sharing, and storing the data. In addition, Cresswell (2014) classified ethical considerations in research (a) prior to the beginning of the study, (b) at the beginning of the study, (c) while collecting and analyzing the data, and (d) while reporting, sharing, and storing the data.

Cohen et al. (2007), in their book "Research Methods in Education," presented a set of initial ethical principles that researchers should consider when conducting educational research (e.g., informed consent, ethical problems endemic in particular research methods, and responsibilities to the research community).

They argued that before the beginning of the research process, some steps must be taken (e.g., paying attention to codes of the ethics, obtaining essential permissions, asking a trusted colleague to study the research plan and look for potential sources of misleading consequences, and planning the study in such a way that reduces the possibility that the findings will be misleading).

They also mentioned that at the beginning of a study, the researchers should consider a number of issues, such as selecting an influential research problem, not forcing participants to sign consent forms, disclosing the aim of the research, respecting the standards and charters of national cultures, being responsible to the academic world, and developing the research's credibility.

Under the category of gathering data, they remarked that researchers should consider a number of issues, such as not deceiving participants, refraining from exploiting participants, implementing the study competently and with due concern for the honor and welfare of the participants, and having legal obligations to human subjects.

They also stated that while analyzing the data, researchers should refrain from being native, refrain from disclosing only positive findings, respect the privacy of subjects, and not fabricate the data, among other considerations.

Finally, regarding factors related to the underwriting, reporting, sharing, and storing of data, researchers should consider some issues as non-plagiarizing, non-disclosing of information that would harm participants, providing safe storage of information and controlling access to it, among other issues.

\section{Empirical Studies}

Shamoo and Resnik (2015) proposed some ethical principles that should be followed when conducting research: (1) honesty, (2) objectivity, (3) integrity, (4) carefulness, (5) openness, (6) respect for intellectual property, (7) confidentiality, (8) responsible publication, (9) responsible mentoring, (10) respect for colleagues, (11) social responsibility, (12) non-discrimination, (13) competence, (14) legality, (15) animal care, and (16) human subjects protection. MacColl, Cooper, Rittenbruch, and Viller (2005, pp. 23-25) examined some of the "ethical problems relevant to performing anthropological action research to clarify and promote distributed collaboration."

In another study, Koulouriotis (2011, pp. 1-15) examined "the ethical considerations of three education researchers collaborating with foreigner English-speaking participants" by means of qualitative data analysis. The researchers are concerned about five issues in research ethics, including (1) informed consent, (2) language and translation, (3) positionality, (4) voice, and (5) working with research ethics boards (REBs).

Guo, Tao, and Gao (2019) mentioned that as seen in the analysis of language teacher education-related studies, it can be argued that future work will continue to examine core issues to produce concrete results for language teacher training. Language teacher education, language teacher awareness, and teacher learning could trigger cognitive changes (e.g., beliefs, awareness, experience, and understanding). Thus, they could be core issues 
that need more attention. Professional learning for language teachers frequently takes place in highly demanding situations, as language teachers often need more money, time, and space to cope with the increasingly complex nature of language teaching. Therefore, we need to focus on various analytical resources (e.g., identity and agency) and insights (e.g., dynamic system theory) to analyze and appreciate what drives language teachers to learn and what supports that drive. Therefore, researchers need to dig into language teachers' motivation and dedication, which receives only a small amount of research attention compared to language learning motivation. Not only will a greater understanding of language teachers' motivation promote continuing professional learning, but it will also improve the learning experiences of students.

We are aware that "language learning and teaching occurs in a dynamic environment, influenced by a variety of circumstances and relationships inside and outside the boundaries of classroom walls" (Gao, 2019, p. 162). The nature of language teaching needs to be thoroughly researched so that specific results can inform the pedagogical decisions of language teachers. Moreover, since language teachers are becoming increasingly important in helping language learners build semiotic tools for self-affirmation in low-resource contexts, it is important for language teachers to become aware of contextual mediations on language learners and their learning.

Ngozwana (2018, pp. 19-28) investigated the ethical difficulties that were specialized in a qualitative research methodology in an African context. These difficulties were related to the concepts of "withdrawal from the study, anonymity and confidentiality." Parsell, Ambler, and Jacenyik-Trawoger (2014) examined some of the reasons underlying educational researchers' challenges in obtaining ethics approval by considering the methods of collaborative action studies. They contradicted ethics clearance. They also provided details of the ongoing process that ultimately results in the approval of ethics, paying particular attention to the different perspectives on the notions of "coercion" and "confidentiality."

In the work of Popoola et al., (2017), the structural equations model in the R programming language was developed and validated to investigate the effect of explicit and implicit strategies of formalizing ethics for decreasing academic cheating by students. Researchers discovered "a significant mediating effect of implicit ethics institutionalization on the relationship between explicit ethics institutionalization and educational cheating among business students" (p. 29). Finally, they argued that academic managers should focus on implicit types of formalization of ethics to regulate student educational cheating.

Dixon and Quirke (2018) carried out a qualitative review of the chapters of ethics in 18 high-selling undergraduate textbooks applicable to courses in research methodology in the sociology field in the USA and Canada. Their findings revealed how experiments were seen as the study plan that were expected to affect the subjects negatively. They also found that "textbooks promote a procedural rather than nuanced approach to ethics and that content in ethics chapters is out of step with scholarly research in research ethics" (p. 12).

According to Sterling and Gass (2017), research ethics are the cornerstone of modern data collection, yet training in various areas of research ethics are often lacking in applied linguistics. Their article explores the reactions that members of the field have towards scenarios in which the ethicality of action cannot be easily identified as right or wrong. Survey respondents read 10 scenarios in which actors completed ambiguous ethical actions and then rated them for (1) their level of ethicality, (2) the frequency of similar issues, and (3) how frequently the respondent believed researchers faced similar issues. The results indicated that situations involving materials covered during ethical review training were rated as being less ethical when compared to items that revolved around issues of academic integrity. Counter-intuitively, experienced researchers rated scenarios as being intrinsically more ethical, indicating that time spent in the field might result in a more lax view of ethics. Finally, participants relied heavily on ethical review board requirements to guide their decisions about what is ethical and what is not. Taken together, these data indicate that a further discussion of research ethics is needed in the field, especially regarding the elements of academic integrity and ethically gray areas.

Olsthoorn and Schut (2018) in their study titled "The ethics of border guarding," tried to (1) describe border guarding as a comparatively rule-guided carrier; (2) outline the purpose and basis of the ethics education that provides border guards for their profession; and (3) suggest a research agenda for the future that develops our understanding of (1) and (2) and helps boost the ethical education of border guards. 
According to new research, the growing concern for ethics in applied linguistics may be attributed to attempts to stem the rising incidence of ethical lapses in order to ensure that the core ethical principles of (1) respect for persons, (2) yielding optimal benefits while minimizing harm, and (3) justice are preserved. By inviting applied linguists to evaluate their methodological practices and those of their peers, De Costa et al. (2020) also argue for the need to develop the ethical dispositions of emerging applied linguists, with a view to create a more robust field.

To develop codes of ethics for other issues, Kafi, Motallebzadeh, and Ashraf (2018) constructed a Professional Ethical Code for Universities' Educational Background according to relevant documents and a semi-structured interview and intended to adapt it to the needs of Iranian EFL university instructors. The full literature review led to four main categories (commitment to the profession, learners, society, and organizations) being included in the code, with several sub-categories for each.

Finally, however, there has not been any attempt to develop a scale for evaluating Iranian EFL teachers' awareness of the code of ethics in research. The present study aims to fill this gap by replying to the following research question.

Q: Is the newly designed questionnaire investigating EFL teachers' awareness of the code of ethics in research valid and reliable?

\section{Methodology}

\section{Participants}

The respondents in this study included EFL teachers at public and private high schools and English language institutes $(\mathrm{N}=272)$. They were selected using convenience sampling, and the participation was entirely optional. It included men and women of various ages and years of teaching experience. The participants had graduated in various English fields such as literature, translation, and teaching with a master's or doctorate degree. The researchers used online platforms and in-person self-administered questionnaire distribution. Most of the participants received the questionnaire via email or social networks like Telegram and WhatsApp, but for others the questionnaires were carried out in-person.

\section{Instrumentation}

\section{EFL Teachers' Awareness of the Code of Ethics}

The Ethical Code of Research Scale is a questionnaire that was designed by the researchers involved in this study. The main factors of this inventory were determined by the theoretical framework of this study. The answers were given on a 5-point Likert scale. The scale includes 59 items and assesses EFL teachers' awareness of the code of ethics in research through five subscales: (1) Before the beginning of the research, (2) the Beginning of the research, (3) Gathering the data, (4), Analyzing the data, and (5) Writing, reporting, sharing, and storing the data. To validate the procedure, the reliability of this scale was obtained using Cronbach's alpha and its validity was measured by the CFA's Structural Equation Modeling approach.

\section{Procedure}

This study aimed to construct a scale investigating an English as a Foreign Language (EFL) teachers' awareness of the code of ethics in research in Iran. According to the categories and standards proposed by Samadi, Motallebzadeh, Ashraf, and Khajavy (2020), almost all of the phases of the development and validation of the questionnaire were carried out in accordance with the instructions provided in Dornyei's (2010) questionnaire development manuals. The investigators went through the following phases to create a reliable and valid questionnaire.

Phase one: Accumulation and generation of items: The first and foremost step for any instrument creation is to study the relevant documentation. This phase has two goals: (1) analysis of the available tools and (2) 
establishing a strong theoretical basis for the instrumentation. The items here were adopted from different references such as Cohen et al. (2007), Cresswell (2014), Koulouriotis (2011), and Shamoo and Resnik (2015).

Phase two: Rating scale design: The rating scale used here was a 5-point Likert scale. The investigators selected the choices from among the five options, including strongly agree, agree, no idea, disagree and strongly disagree.

Phase three: The private data section: Personal demographic details used in this inventory included data about sex, age, years of teaching experience, level/s they teach, highest degree earned, and major of study.

Phase four: Experts item checking: Upon item development in the preceding phases, the investigators assembled a group of five experts and non-experts on which to test their comprehensibility and accuracy.

Phase five: Items and item revision: Revisions and modifications were made to items.

Phase six: Piloting and analysis of items: In this stage, the designed questionnaire was distributed among EFL teachers. Finally, the designed questionnaire went through a pilot study to examine 1) the content and understandability of the items, and 2) the psychometric features of the questionnaires such as their reliability and validity. The data analysis of these draft questionnaires presented evidence of the questionnaires construct validity to understand whether this instrument actually measured the constructs they claimed they are measuring. This analysis was performed through AMOS using confirmatory factor analysis (CFA).

Phase seven: Reliability index: The Cronbach Alpha Coefficient was used to test the internal reliability of the questionnaire in this analysis.

Phase eight: Validation: The validity of the scale was measured by running CFA through Structural Equation Modeling approach.

Finally, the model of EFL teachers' awareness of the code of ethics in research was proposed.

\section{Results}

\section{Test of Normality}

The Kolmogorov-Smirnov test was employed to test the normality of the spread of the data. This technique is used to specify if the dispersion diverges from a relative normal distribution. If the p-value is non-significant ( $p>$.05), we can assume that the distribution of a sample does not vary significantly from a normal distribution, thus it is normal when the $\mathrm{p}$-value $(\mathrm{p}<.05)$ is significant, then the distribution is not ordinary. Table 4.1 reports the findings of the Kolmogorov-Smirnov test.

\section{Table 1}

The Results of the K-S Test

\begin{tabular}{lccl}
\hline & Statistic & df & Sig. \\
\hline F1 & .73 & 272 & .06 \\
F2 & .73 & 272 & .06 \\
F3 & .64 & 272 & .09 \\
F4 & .41 & 272 & .11 \\
F5 & .69 & 272 & .07 \\
\hline
\end{tabular}

In the Research Inventory, the received sig value for all sub-constructs of the Code of Ethics was higher than .05 : $\mathrm{F} 1=.06, \mathrm{~F} 2=.06, \mathrm{~F} 3=.09, \mathrm{~F} 4=.11$, and $\mathrm{F} 5=.07$. Thus, it may be inferred confidently that the data is normally spread across all variables and parametric tests can be utilized. 


\section{Descriptive Statistics}

Table 4.2 displays the descriptive statistics of the code of ethics' sub-constructs in the research scale, including mean, standard deviation, and maximum and minimum scores. In the following section, comparisons of these scores are presented. Because the number of items in the different subscales of this scale varied, an average item score was calculated for each sub-construction, varying from one to five in the last column. The potential score range for F1 and F4 with six items each varies from 6 to 30, for F2 with 10 items between 10 and 50, for F3 with 20 items between 20 and 100, and for F5 with 17 items between 17 and 85 points.

Table 2

Descriptive Statistics of Sub-Constructs of the Code of Ethics in the Research Scale

\begin{tabular}{lcccccc}
\hline & N & Minimum & Maximum & Mean & Std. Deviation & Mean per item \\
\hline F1 & 272 & 6.00 & 30.00 & 24.55 & 4.03 & 4.09 \\
F2 & 272 & 10.00 & 50.00 & 37.74 & 5.87 & 3.77 \\
F3 & 272 & 21.00 & 105.00 & 84.23 & 13.17 & 4.21 \\
F4 & 272 & 6.00 & 30.00 & 19.41 & 4.92 & 3.23 \\
F5 & 272 & 17.00 & 144.00 & 68.36 & 11.04 & 4.02 \\
Overall Scale & 272 & 60.00 & 328.00 & 234.31 & 31.03 & 3.97 \\
\hline
\end{tabular}

The five sub-constructs in Table 4.2 included: (F1) before the beginning of the research, (F2) the Beginning of the research, (F3) Gathering the data, (F4), Analyzing the data, and (F5) Writing, reporting, sharing, and storing the data. As shown in Table 4.2, among the five sub-constructs of the Code of Ethics in the research scale, F3 (Gathering the data) had the highest mean score (4.21) and F4 (Analyzing the data) had the lowest mean score (3.23). The minimum score for the overall scale was 60 and the maximum score is 328 . The mean score of overall scale is 234.31 with a standard deviation of 31.03. Furthermore, the table shows that the number of participants was 272 in this study.

Validation involves gathering any piece of information that helps us justify our interpretations of the test results. This process includes calculating the reliability and construct-related validity of the instruments (Ary, Cheser, \& Sorensen, 2010).

The designed questionnaire went through a pilot study to examine 1) the content and the understandability of the items, and 2) the psychometric characteristics of the questionnaires including the reliability and validity. The sample of the pilot study included 272 teachers of TEFL. A section was added to the beginning of the questionnaires introducing the purpose of the research, in addition to some demographic information such as the participants' years of teaching experience, gender, age, degree, major, and the number of articles that have been published. The teachers answered the questionnaires. The data analysis of these draft questionnaires included providing proofs for the construct validity of the questionnaire to examine whether this instrument really measured the constructs they claimed were being measured. This analysis was performed through Amos using confirmatory factor analysis.

To determine the questionnaire's reliability, Cronbach's alpha test was used. This index is highly useful when computing the internal consistency of a scale. The following parts report these indexes for all subscales of the designed questionnaire.

In this part, all the different subcomponents of the teachers' awareness of the code of ethics in research scale were examined one by one.

As the statistics show, the designed questionnaire obtained appropriate Cronbach's alpha indexes as a whole, as well as in its sub-constructs: $\mathrm{F} 1=.81, \mathrm{~F} 2=.81, \mathrm{~F} 3=.94, \mathrm{~F} 4=.79$, and $\mathrm{F} 5=.85$. This table also indicates that the reliability of the overall questionnaire was .94 , which suggests very good reliability for the scale with this sample. It should be added that because one item was deleted in this part of the study, in the final draft of the questionnaire, the numbering of items changed (See Appendix A for the questionnaire). 
Table 3

Number of Items and Cronbach's Alpha Indexes Following Item and Reliability Analysis for the Teachers' Awareness of the Code of Ethics in Research Scale

\begin{tabular}{cccc}
\hline Scale & Subscales & Number of items & Cronbach's alpha \\
\hline & F1 & 6 & .81 \\
Teachers' awareness of the code of ethics in research scale & F2 & 9 & .81 \\
& F3 & 20 & .94 \\
& F4 & 6 & .79 \\
\hline
\end{tabular}

Confirmatory factor analysis was used to examine the validity of the developed scale investigating EFL teachers' awareness of the code of ethics in research. The relationship between each sub-factor of the proposed model was evaluated based on the CFA analysis, and the results are displayed in Figure 1. The goodness of the fit indices was used to test the model fitness. See Figure 1 for the model by all parameter loadings.

Table 4 displays the goodness of the fit indices. In this research $\chi 2 / \mathrm{df}$ should be smaller than 3 , GFI and CFI should be more than .90, and RMSEA should be lower than .08 in order to have a fit model.

Table 4

The Goodness of the Fit Indices

\begin{tabular}{lcccccc}
\hline & $\mathbf{X} 2$ & $\mathbf{d f}$ & $\mathbf{X} \mathbf{2} \mathbf{d f}$ & GFI & CFI & RMSEA \\
\hline Acceptable fit & & & $<3$ & $>.90$ & $>.90$ & $<.08$ \\
Model & 4107.33 & 1558 & 2.59 & .95 & .93 & .07 \\
\hline
\end{tabular}

According to Table 4, all the goodness of fit indices were inside the reasonable range. Therefore, the questionnaire enjoyed acceptable validity. $\chi 2$ /df was smaller than 3 , GFI and CFI were more than .90, RMSEA was lower than .08. Figure 1 shows a CFA model of the teachers' awareness of the code of ethics in research scale.

\section{Figure 1}

CFA Model of the Scale for Teachers' Awareness of the Code of Ethics in Research

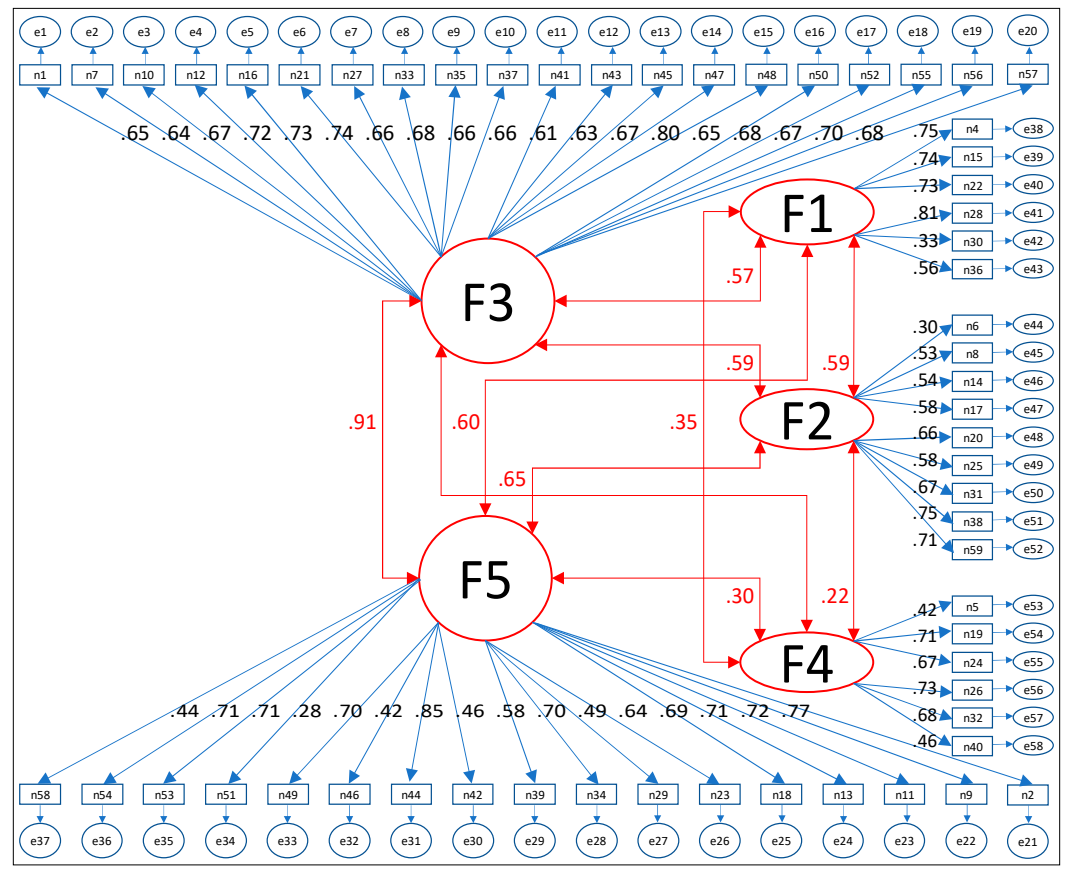

Note: $\mathrm{F} 1=$ Before the beginning of the research, $\mathrm{F} 2=$ the Beginning of the research, $\mathrm{F} 3=$ Gathering the data, $\mathrm{F} 4=$ Analyzing the data, and $\mathrm{F} 5=$ Writing, Reporting, sharing, and storing the data. 
As Figure 1 illustrates, teachers' awareness of the code of ethics in research scale has 5 sub-constructs. Loadings of the first factor, before the beginning of the research, with 6 items ranged from .33 to .81 . Loadings of the second factor, the beginning of the research, with 9 items ranged from .30 to .75 . Moreover, loadings of the third factor, gathering the data, with 20 items ranged from .60 to .74. In addition, loadings of the fourth factor, analyzing data, with 6 items ranged from .41 to .79. Finally, loadings of the last factor, writing, reporting, sharing, and storing the data, with 17 items, ranged from .44 to .77. There were positive significant correlations between all five sub-constructs. The highest correlation was between F3 and F5 (.91) and the lowest correlation was between F2 and F4 (.22). Therefore, the scale enjoyed acceptable validity.

\section{Discussion}

The primary objective of the present research was to construct a scale of EFL teachers' awareness of the code of research ethics in the Iranian context.

Various pedagogical implications arose from the outcomes of this research. Based on the findings obtained, the study reveals a new model of EFL teacher awareness of the code of ethics in research, which can help research institutions with recruitment. The findings of this study can also be used to promote professionalism in ELT, and they can be considered as complementary features alongside professional development programs regarding language teaching and research. They also constitute a basis for developing and implementing teacher education policies and teacher training programs. Likewise, such a study could have consequences for EFL instructors and educational supervisors in terms of enhancing their success in ELT field research. Thus, the outcomes of this study can guide Iranian ELT professionals as they work towards setting standards in research for Iranian EFL teacher professional development. Ethical codes can be considered one of the most realistic ways to provide proper insights for EFL teachers regarding how to address different ethical issues that may be related to research.

Furthermore, the findings of this study may inform EFL teachers about the importance of caring about ethical issues in research and trying to keep themselves up to date on this important matter. They must raise their awareness of research ethics in the ELT domain. In fact, the ethical issues that emerged from the interviews showed that Iranian EFL teachers should improve their ethical conduct in research.

Teacher educators, therefore, play a crucial role in guiding EFL teachers towards an understanding of the code of ethics in science. They need to arrange workshops and courses, such as in-service training courses for teachers, with the specific goal of developing teachers' awareness, knowledge, and expertise and concentrate on research that can help teachers conduct research ethically.

The questionnaire went through a pilot study. The data analysis of the draft questionnaires presented proofs of the questionnaire's construct validity to see whether this instrument really measured the constructs they claimed to be measuring. This analysis was performed through Amos using CFA. Cronbach's alpha index was used to test the questionnaire's reliability. Analyzing the reliability of teachers' awareness of the code of ethics in research questionnaire showed that it achieved an acceptable Cronbach's alpha of .94.

In addition, a CFA was used to check the validity of the developed EFL teachers' awareness of the code of ethics in research scale. The relationship across each sub-factor of the offered model was evaluated based on the CFA analysis. All goodness of fit indices were within a reasonable range. Therefore, the scale had reasonable validity.

In terms of designing and validating a scale to investigate teachers' awareness of the code of ethics in research, no study has been conducted. However, a variety of scales have been planned and tested for other issues. For example, Motallebzadeh, Kafi, and Ashraf (2018) developed a professional ethics code for a university academic context. Their study was designed for the context of universities, although the present study was in the context of high schools and language institutes. In addition, their scale included all four components of the code of professional ethics (namely the commitment of teachers to learners, the commitment of teachers to society, the commitment of teachers to their profession, and the commitment of teachers to organizations). However, 
the present study included five components. Nevertheless, both studies were conducted in the EFL context of Iran.

Ethics and ethical principles are culture-bound. They may differ in diverse cultural settings and contexts. Therefore, further research projects can be administered in other countries with different cultural backgrounds and in various contexts, which might yield dissimilar but interesting results. They will, however, pave the way for a cross-comparison of discoveries. Further work can be carried out to examine the relationship between Iranian EFL teachers' awareness of the code of ethics in research with other variables such as the professional development of teachers and the variables related to teachers. Further research can be implemented to design and implement a practical study in the form of a survey to gauge Iranian teachers' degree of familiarity with these ethical considerations or other dimensions or sub-dimensions of research ethics in applied linguistics.

\section{(De) Limitations of the Study, and Suggestions for Further Research}

This investigation had some limitations. The participants of the study were chosen using convenience sampling. Another limitation was related to the issue of one country (Iran), as different countries have different systems of education. Thus, the findings were considered within only one country. This study should be repeated with more participants from various parts of the world and with methods that guarantee a high level of randomization and greater generalizability. This can also lay the foundation for cross-comparisons of the findings. Difficult policies of data collection in different countries make it impossible to compare different countries' codes of ethics.

This study had some delimitations too. These were imposed by the researcher to narrow the scope of this study. For the current study, only EFL teachers from different cities in Iran were included. In addition, the researcher tried to include a complete set of demographic data (both genders, and both novice and experienced teachers). However, there might be additional demographic characteristics and factors related to teachers' methods of reflective teaching and their critical thinking that are important but were excluded from the present study.

Ethics and ethical principles are culture-bound. They may differ in diverse cultural settings and contexts. Therefore, similar research can be carried out in other countries with different cultural backgrounds and in various contexts and such research might yield dissimilar yet interesting results. It could also become the basis for a cross-comparison of the findings. Further research can be implemented to explore the relationship between Iranian EFL teachers' awareness of the code of ethics in research with other variables, such as teachers' professional development and teacher-related variables.

\section{Conclusion}

Even though literature on the EFL context provides little discussion on the investigators' ethical concerns as educators, the outcomes of this study indicate that this is a popular subject that should be addressed. In this study, EFL teachers' awareness of the code of ethics in research was developed and validated. The designed questionnaire achieved an appropriate Cronbach's alpha of .94 overall and for its sub-constructs. In addition, a CFA was used to determine the quality of the inventory. The relationship between each sub-factor of the proposed model was evaluated based on this analysis. All of the fit indices goodness values were reasonable. The inventory thus had acceptable credibility.

Despite the scarcity of examinations and models related to the code of ethics in research in Iran in an EFL context, promoting EFL teachers' awareness of the code of ethics in research is still a pertinent task, given the increasing need for ethical researchers in the era of globalization. As such, investigating teachers' awareness of the code of ethics in research in Iran and other EFL contexts is of paramount significance.

Thus, the researcher hopes that the newly-developed instrument for evaluating the awareness of the code of ethics for research by Iranian EFL teachers will be given attention and eventually implemented at the national level so that we may assure consistency in EFL teachers' quality assurance. The ethical standards could be a starting point for researchers who teach foreign students how to speak English. Researchers constantly examine 
their own practices, recognizing that ethics are the duty of the individual investigator and that ethical conduct is a continuous and iterative process.

The issues posed by this study are unlikely to be resolved quickly or neatly in the immediate future, and our goal here is not to recommend a set of rules to be followed by researchers. Indeed, this research clearly illustrates some aspects in which ethics play a central role in studies in the Iranian EFL context, and we expect that it will offer a chance for contemplation and consideration by researchers. We predict that by implementing these kinds of studies, research can be further progressed in the EFL profession. As Hostetler (2005) claims, "our ultimate aim as researchers and educators is to serve people's well-being" (p. 16). We will try to ensure that the voices of our subjects are heard by giving serious consideration to the ethical standards and matters concerning research in the EFL context (Koulouriotis, 2011).

\section{Conflict of Interest}

The authors declare that they have no conflict of interest.

\section{References}

Ary, D., Cheser, L. Ch., \& Sorensen, Ch. K. (2010). Introduction to research in education. Cengage Learning.

Baer, J. M. (2010). European textbook on ethics in research. European Commission.

Best, J. W., \& Cahn, J. V. (2006). Research in education. Pearson Education, Inc.

The Council for the Teaching Profession in Malta. (2012). Teachers' code of ethics and practice. https://education. gov.mt/en/.../New\%20Code\%20of\%20Ethics\%20Doc\%20EN.pdf

Cohen, L., Manion, L., \& Morrison, K. (2007). Research methods in education. Routledge.

Creswell, J. W. (2014). Research design: Qualitative, quantitative and mixed methods approaches (4th ed.). Sage.

Davies, A. (2004). Introduction: Language testing and the golden rule. Language Assessment Quarterly, 1(2), 97107. https://doi.org/10.1080/15434303.2004.9671778

De Costa, P. I., Sterling, S., Lee, J., Li, W., \& Rawal, H. (2020). Research tasks on ethics in applied linguistics. Language Teaching, 1-13. https://doi.org/10.1017/s0261444820000257

Dixon, Sh., \& Quirke, L. (2018). What's the harm? The coverage of ethics and harm avoidance in research methods textbooks. Teaching Sociology, 46(1), 12-24. https://doi.org/10.1177/0092055X17711230

Dornyei, Z. (2010). Questionnaires in second language research: Construction, administration, and processing (2nd ed.). Routledge.

Farhady, H. (1999). Ethics in language testing. Moddaress Journal of Human Sciences, 3(11), 447-464.

Freeman, N. K. (2000). Professional ethics: A cornerstone of teachers' pre-service curriculum. Action in Teacher Education, 22(3), 12-18. https://doi.org/10.1080/01626620.2000.10463015

Gao, X. (2019). The Douglas Fir Group Framework as a resource map for language teacher education. The Modern Language Journal, 103, 161-166. https://doi.org/10.1111/modl.12526

Guo, Q., Tao, J., \& Gao, X. (2019). Language teacher education in System. System, 82, 132-139. https://doi. org/10.1016/j.system.2019.04.001

Hostetler, K. (2005). What is "good" education research? Education Research, 34(6), 16-21. https://doi. org/10.3102/0013189X034006016

Kafi, Z., Motallebzadeh, Kh., \& Ashraf, H. (2018). Developing, localizing \& validating code of professional ethics through PLS-SEM: EFL university instructors' perspectives. Cogent Education, 5(1), 1-23. https://doi.org/10. 1080/2331186X.2018.1492340

Koulouriotis, J. (2011). Ethical considerations in conducting research with non-native speakers of English. TESL Canada Journal, 5, 1-15. https://doi.org/10.18806/tesl.v28i0.1078

MacColl, I., Cooper, R., Rittenbruch, M., \& Viller, S. (2005). Watching ourselves watching: Ethical issues in ethnographic action research. In Proceedings of OZCHI 2005 (pp. 1-4). ACM.

Mazur, D. J. (2007). Evaluating the science and ethics of research on humans: a guide for IRB members.

Ngozwana, N. (2018). Ethical dilemmas in qualitative research methodology: Researcher's reflections. International Journal of Educational Methodology, 4(1), 19-28. https://doi.org/10.12973/ijem.4.1.19 
Olsthoorn, P., \& Schut, M. (2018). The ethics of border guarding: a first exploration and a research agenda for the future. Ethics and Education, 13(2), 157-171. https://doi.org/10.1080/17449642.2018.1443051

Özturk, S. (2010). The opinions of preschool teachers about ethical principles. Journal of Educational Sciences: Theory \& Practice, 10(1), 393-418.

Parsell, M., Ambler, T., \& Jacenyik-Trawoger, Ch. (2014). Ethics in higher education research. Studies in Higher Education, 39(1), 166-179. https://doi.org/10.1080/03075079.2011.647766

Popoola, I., Garner, B., Ammeter, A., Krey, N., Beu Ammeter, D., \& Schafer, S. (2017). How does ethics institutionalization reduce academic cheating? Journal of Education for Business, 92(1), 29-35. https://doi.or $\mathrm{g} / 10.1080 / 08832323.2016 .1274710$

Samadi, F., Motallebzadeh, Kh., Ashraf, H., \& Khajavy, H. (2020). Developing a model for Iranian EFL teachers' awareness of the code of ethics in research [Unpublished doctoral dissertation)]. Islamic Azad University of Torbat-e Heydarieh.

Shamoo, A., \& Resnik, D. (2015). Responsible conduct of research (3rd ed.). Oxford University Press.

Sterling, S., \& Gass, S. (2017). Exploring the boundaries of research ethics: Perceptions of ethics and ethical behaviors in applied linguistics research. System, 70, 50-62. https://doi.org/10.1016/j.system.2017.08.010

Thrasher, R. (2011). The Role of a language testing code ethics in the establishment of a code of practice. Language Assessment Quarterly, 1 (2), 1-19. https://doi.org/10.1080/15434303.2004.9671782

World Medical Association: Declaration of Helsinki. (2013). Ethical principles for medical research involving human subjects. JAMA, 310(20), 2191-2194. 


\section{Appendix}

\section{EFL teachers' awareness of the code of ethics in research scale}

Dear respondent,

This survey is intended to explore the awareness of EFL teachers about the code of ethics in research when participating in the research process. The information that you reveal to us through this questionnaire is kept anonymous and will only be used for research purposes.

The items of this questionnaire cover areas related to the following headings: (1) Before the beginning of the research, (2) the Beginning of the research, (3) Gathering the data, (4), Analyzing the data, and (5) Writing, reporting, sharing, and storing the data.

\section{A. Teachers' information: Please mark the part that best matches your status.}

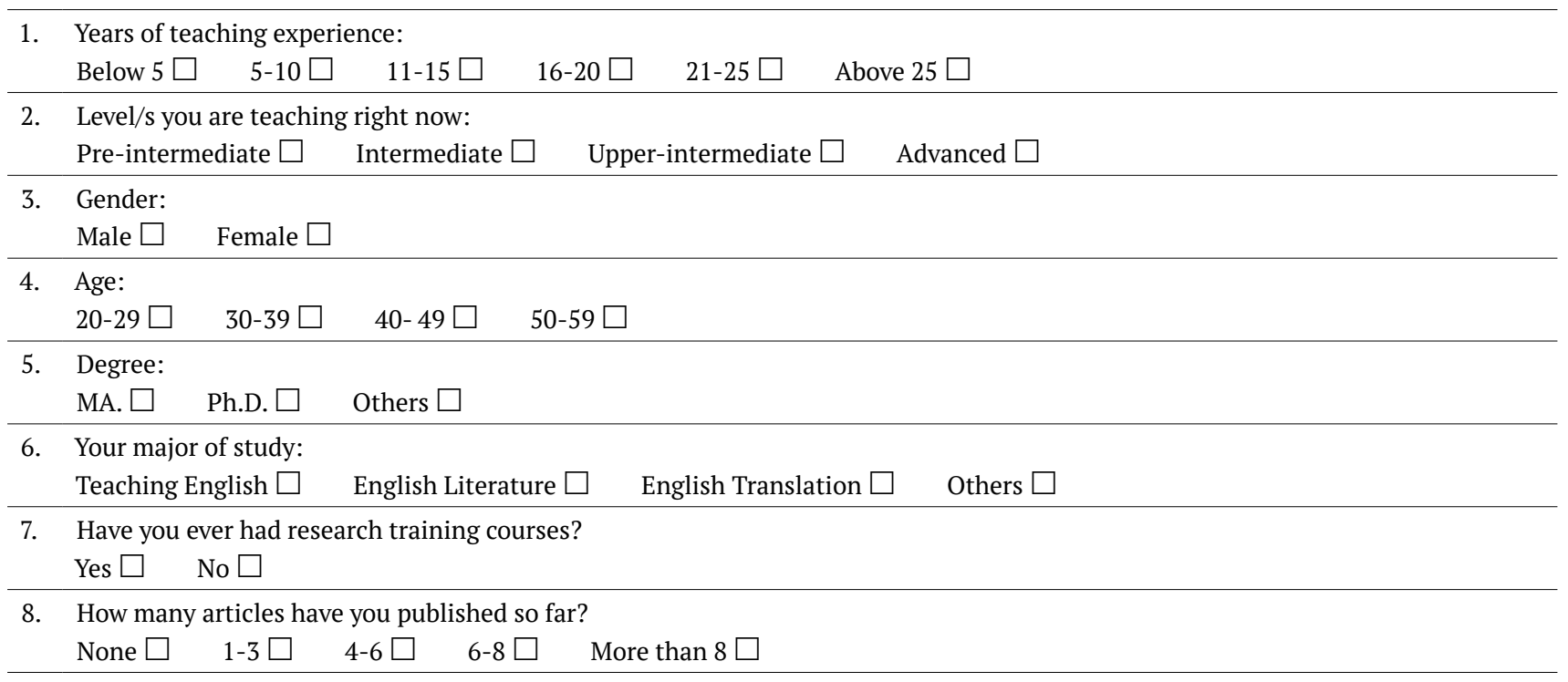

B. Please mark the part that best matches your status. There is no wrong or right answer.

\begin{tabular}{|c|c|c|c|c|c|c|}
\hline No & Statement & $\begin{array}{l}\text { Strongly } \\
\text { disagree }\end{array}$ & Disagree & No idea & Agree & $\begin{array}{l}\text { Strongly } \\
\text { agree }\end{array}$ \\
\hline & As an EFL teacher, in research, .... & $\square$ & $\square$ & $\square$ & $\square$ & $\square$ \\
\hline 1 & $\begin{array}{l}\text { I do not deceive participants about important aspects that would } \\
\text { influence their willingness to participate. }\end{array}$ & $\square$ & $\square$ & $\square$ & $\square$ & $\square$ \\
\hline 2 & $\begin{array}{l}\text { I finalize proof of compliance with ethical considerations and a lack } \\
\text { of conflict of interest. }\end{array}$ & $\square$ & $\square$ & $\square$ & $\square$ & $\square$ \\
\hline 3 & I am careful with the reliability and validity of the instruments. & $\square$ & $\square$ & $\square$ & $\square$ & $\square$ \\
\hline 4 & I know how to conduct research. & $\square$ & $\square$ & $\square$ & $\square$ & $\square$ \\
\hline 5 & I ignore the data that proves or disproves my personal hypotheses. & $\square$ & $\square$ & $\square$ & $\square$ & $\square$ \\
\hline 6 & I feel responsible to the research community. & $\square$ & $\square$ & $\square$ & $\square$ & $\square$ \\
\hline 7 & $\begin{array}{l}\text { I conduct the research competently and with due concern for the } \\
\text { honor and welfare of the participants. }\end{array}$ & $\square$ & $\square$ & $\square$ & $\square$ & $\square$ \\
\hline
\end{tabular}




\begin{tabular}{|c|c|c|c|c|c|c|}
\hline 8 & I select an influential research problem. & $\square$ & $\square$ & $\square$ & $\square$ & $\square$ \\
\hline 9 & $\begin{array}{l}\text { I feel a responsibility to provide safe storage for the informationI } \\
\text { collect and control access to it. }\end{array}$ & $\square$ & $\square$ & $\square$ & $\square$ & $\square$ \\
\hline 10 & $\begin{array}{l}\text { I ensure that all participants, not only an experimental group, receive } \\
\text { the advantages from the effective treatments. }\end{array}$ & $\square$ & $\square$ & $\square$ & $\square$ & $\square$ \\
\hline 11 & I avoid duplicating or gradual publications. & $\square$ & $\square$ & $\square$ & $\square$ & $\square$ \\
\hline 12 & $\begin{array}{l}\text { I respect research site so that they are not left disorganized after a } \\
\text { research study. }\end{array}$ & $\square$ & $\square$ & $\square$ & $\square$ & $\square$ \\
\hline 13 & $\begin{array}{l}\text { I retain raw data and other materials including procedures, } \\
\text { instruments. }\end{array}$ & $\square$ & $\square$ & $\square$ & $\square$ & $\square$ \\
\hline 14 & $\begin{array}{l}\text { I am sensitive to any locally established institutional policies or } \\
\text { standards for implementing research. }\end{array}$ & $\square$ & $\square$ & $\square$ & $\square$ & $\square$ \\
\hline 15 & $\begin{array}{l}\text { I plan my study so as to reduce the possibility that findings will be } \\
\text { misleading. }\end{array}$ & $\square$ & $\square$ & $\square$ & $\square$ & $\square$ \\
\hline 16 & I keep careful records of data collection. & $\square$ & $\square$ & $\square$ & $\square$ & $\square$ \\
\hline 17 & I develop the integrity of research. & $\square$ & $\square$ & $\square$ & $\square$ & $\square$ \\
\hline 18 & I communicate my study results and share my findings with others. & $\square$ & $\square$ & $\square$ & $\square$ & $\square$ \\
\hline 19 & I do not fabricate, falsify, or misrepresent data. & $\square$ & $\square$ & $\square$ & $\square$ & $\square$ \\
\hline 20 & I respect my colleagues and treat them fairly. & $\square$ & $\square$ & $\square$ & $\square$ & $\square$ \\
\hline 21 & $\begin{array}{l}\text { I do not force the subjects to participate or sign consent forms and let } \\
\text { them take part freely }\end{array}$ & $\square$ & $\square$ & $\square$ & $\square$ & $\square$ \\
\hline 22 & I discuss authorship for publication with my colleagues. & $\square$ & $\square$ & $\square$ & $\square$ & $\square$ \\
\hline 23 & I communicate in clear simple, suitable language. & $\square$ & $\square$ & $\square$ & $\square$ & $\square$ \\
\hline 24 & I choose the most suitable statistical analysis. & $\square$ & $\square$ & $\square$ & $\square$ & $\square$ \\
\hline 25 & $\begin{array}{l}\text { I seek to encourage the good of society and to avoid or minimize } \\
\text { social harms. }\end{array}$ & $\square$ & $\square$ & $\square$ & $\square$ & $\square$ \\
\hline 26 & $\begin{array}{l}\text { I respect the privacy of participants and consider issues of anonymity } \\
\text { and confidentiality. }\end{array}$ & $\square$ & $\square$ & $\square$ & $\square$ & $\square$ \\
\hline 27 & $\begin{array}{l}\text { I inform the participants about the likelihood risks included in the } \\
\text { study and of potential outcomes for them. }\end{array}$ & $\square$ & $\square$ & $\square$ & $\square$ & $\square$ \\
\hline 28 & $\begin{array}{l}\text { I have received suitable approval from host institutions or } \\
\text { organizations. }\end{array}$ & $\square$ & $\square$ & $\square$ & $\square$ & $\square$ \\
\hline 29 & I do not disclose information that would hurt participants. & $\square$ & $\square$ & $\square$ & $\square$ & $\square$ \\
\hline 30 & I try to improve my professional research competency. & $\square$ & $\square$ & $\square$ & $\square$ & $\square$ \\
\hline 31 & I respect standards and charters of domestic cultures. & $\square$ & $\square$ & $\square$ & $\square$ & $\square$ \\
\hline 32 & I refrain from disclosing only positive findings. & $\square$ & $\square$ & $\square$ & $\square$ & $\square$ \\
\hline 33 & $\begin{array}{l}\text { Before participating in the studyI get informed consent from the } \\
\text { study participants. }\end{array}$ & $\square$ & $\square$ & $\square$ & $\square$ & $\square$ \\
\hline 34 & I do not plagiarize or self-plagiarize. & $\square$ & $\square$ & $\square$ & $\square$ & $\square$ \\
\hline 35 & I have legal obligations to human subjects. & $\square$ & $\square$ & $\square$ & $\square$ & $\square$ \\
\hline 36 & I know relevant rules and institutional and governmental policies. & $\square$ & $\square$ & $\square$ & $\square$ & $\square$ \\
\hline
\end{tabular}




\section{DEVELOPING A MODEL FOR THE EVALUATION OF IRANIAN EFL TEACHERS' AWARENESS}

\begin{tabular}{|c|c|c|c|c|c|c|}
\hline 37 & $\begin{array}{l}\text { I have a responsibility to be cautious of cultural, gender, religious, and } \\
\text { other important differences within the study population. }\end{array}$ & $\square$ & $\square$ & $\square$ & $\square$ & $\square$ \\
\hline 38 & I disclose the aim of the research. & $\square$ & $\square$ & $\square$ & $\square$ & $\square$ \\
\hline 39 & $\begin{array}{l}\text { I avoid misrepresenting authorship, evidence, data, results, or } \\
\text { conclusions. }\end{array}$ & $\square$ & $\square$ & $\square$ & $\square$ & $\square$ \\
\hline 40 & $\begin{array}{l}\text { I avoid "taking sides" and only negotiate the results that put the } \\
\text { participants in a favorable light. }\end{array}$ & $\square$ & $\square$ & $\square$ & $\square$ & $\square$ \\
\hline 41 & I promote trust with the participants. & $\square$ & $\square$ & $\square$ & $\square$ & $\square$ \\
\hline 42 & $\begin{array}{l}\text { I do not recruit ghost- writers to do my research or write my research } \\
\text { text as the author. }\end{array}$ & $\square$ & $\square$ & $\square$ & $\square$ & $\square$ \\
\hline 43 & $\begin{array}{l}\text { I oppose discriminating against participants on the grounds of gender, } \\
\text { race, nationality or any other irrelevant components of academic } \\
\text { integrity and dignity. }\end{array}$ & $\square$ & $\square$ & $\square$ & $\square$ & $\square$ \\
\hline 44 & I consider corresponding issues and ordering of the names. & $\square$ & $\square$ & $\square$ & $\square$ & $\square$ \\
\hline 45 & I prevent or minimize bias or self-deception. & $\square$ & $\square$ & $\square$ & $\square$ & $\square$ \\
\hline 46 & I cite funding resources. & $\square$ & $\square$ & $\square$ & $\square$ & $\square$ \\
\hline 47 & $\begin{array}{l}\text { I am honest with participants about communicating the purposes of } \\
\text { the study. }\end{array}$ & $\square$ & $\square$ & $\square$ & $\square$ & $\square$ \\
\hline 48 & I compensate the participants for their time, attempts, and cooperation. & $\square$ & $\square$ & $\square$ & $\square$ & $\square$ \\
\hline 49 & I am exact in reporting the data. & $\square$ & $\square$ & $\square$ & $\square$ & $\square$ \\
\hline 50 & I keep a good relationship with the participants. & $\square$ & $\square$ & $\square$ & $\square$ & $\square$ \\
\hline 51 & $\begin{array}{l}\text { I avoid overlapping publications and do not submit the article to two } \\
\text { or more journals simultaneously. }\end{array}$ & $\square$ & $\square$ & $\square$ & $\square$ & $\square$ \\
\hline 52 & $\begin{array}{l}\text { I try to minimize invasiveness by intervening with the participants or } \\
\text { setting from which data are gathered. }\end{array}$ & $\square$ & $\square$ & $\square$ & $\square$ & $\square$ \\
\hline 53 & I am exact in my citations. & $\square$ & $\square$ & $\square$ & $\square$ & $\square$ \\
\hline 54 & I am open to criticism and new ideas. & $\square$ & $\square$ & $\square$ & $\square$ & $\square$ \\
\hline 55 & I avoid gathering detrimental information. & $\square$ & $\square$ & $\square$ & $\square$ & $\square$ \\
\hline 56 & I refrain from exploiting the participants. & $\square$ & $\square$ & $\square$ & $\square$ & $\square$ \\
\hline 57 & I respect probable power imbalances. & $\square$ & $\square$ & $\square$ & $\square$ & $\square$ \\
\hline 58 & $\begin{array}{l}\text { I consider who the owner of the data is when writing, reporting, } \\
\text { sharing, and storing the data. }\end{array}$ & $\square$ & $\square$ & $\square$ & $\square$ & $\square$ \\
\hline 59 & $\begin{array}{l}\text { I avoid reckless mistakes and incompetence, and examine my own } \\
\text { work and the work of my colleagues carefully and critically. }\end{array}$ & $\square$ & $\square$ & $\square$ & $\square$ & $\square$ \\
\hline
\end{tabular}

